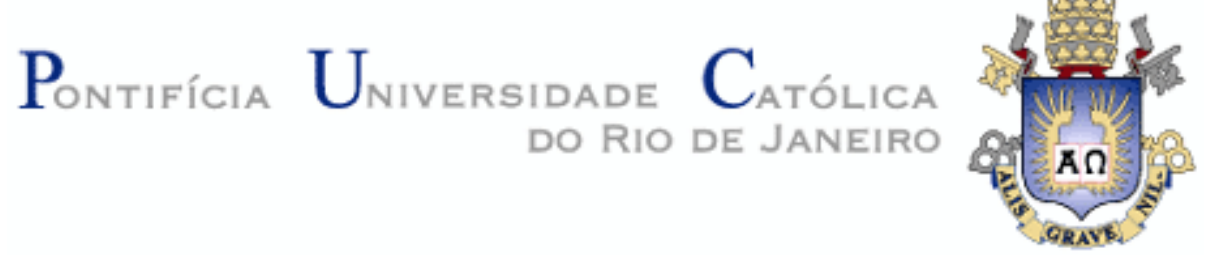

Beatriz Soares de Araujo Ferreira

\title{
Um estudo sobre as conexões \\ afetivas no autismo
}

Dissertação de Mestrado

Dissertação apresentada como requisito parcial para obtenção do grau de Mestre pelo Programa de Pós-graduação em Psicologia (Psicologia Clínica) do Departamento de Psicologia da PUCRio.

Orientadora: Prof. Carolina Lampreia

Rio de Janeiro

Abril de 2014 
Beatriz Soares de Araujo Ferreira

\section{Um estudo sobre as conexões \\ afetivas no autismo}

Dissertação apresentada como requisito parcial para obtenção do grau de Mestre pelo Programa de PósGraduação em Psicologia (Psicologia Clínica) do Departamento de Psicologia do Centro de Teologia e Ciências Humanas da PUC-Rio. Aprovada pela Comissão Examinadora a baixo assinada.

Profa. Carolina Lampreia Orientadora Departamento de Psicologia - PUC-Rio

Profa. Solange Jobim e Souza Departamento de Psicologia - PUC-Rio

Profa. Maryse Helena Felippe de Oliveira Suplino Instituto Ann Sullivan

Profa. Denise Berruezo Portinari Coordenadora Setorial de Pós-Graduação e Pesquisa do Centro de Teologia e Ciências Humanas - PUC-Rio 
Todos os direitos reservados. É proibida a reprodução total ou parcial do trabalho sem autorização da universidade, da autora e da orientadora.

\section{Beatriz Soares de Araujo Ferreira}

Graduou-se em Psicologia pela Universidade Santa Úrsula em 2003, é especialista em Saúde Mental pela ENSP/Fiocruz e especialista em Psicologia Clínica pela PUC-Rio. Atua como psicóloga clínica realizando atendimentos de adultos e crianças.

Ficha Catalográfica

Ferreira, Beatriz Soares de Araujo

Um estudo sobre as conexões afetivas no autismo / Beatriz Soares de Araujo Ferreira ; orientadora: Carolina Lampreia. - 2014.

71 f. ; $30 \mathrm{~cm}$

Dissertação (mestrado)-Pontifícia Universidade Católica do Rio de Janeiro, Departamento de Psicologia, 2014.

Inclui bibliografia 

que ganhei ao final dessa jornada. 


\section{Agradecimentos}

Primeiramente a Deus, pois sem ele nada seria possível...

À Carolina Lampreia, pela sua orientação precisa, dedicação e paciência.

À PUC-Rio, pelos auxílios concedidos, que tornaram este trabalho possível.

Aos meus pais, pela educação, incentivo e carinho.

Ao meu marido André Luiz Bonfatti Gomes, que sempre acreditou que seria possível, pelo seu apoio e amor de todas as horas.

Às amigas Carol Salviano e Caía por compartilhar as angústias e ansiedades.

Às amigas, Viviane e Vanessa pela força e incentivo.

À Ilma Rosa, pelo seu apoio.

Ao Arthur, que muito me ensinou sobre afeto no autismo.

Aos professores do departamento e a Marcelina por seus ensinamentos e ajuda.

Aos familiares e amigos que me estimularam. Em especial à Sandra e à minha mãe que me ajudaram com meu maior presente contribuindo para o término do trabalho. 


\section{Resumo}

Ferreira, Beatriz Soares de Araujo; Lampreia, Carolina. Um estudo sobre as conexões afetivas no autismo. Rio de Janeiro, 2014. 71p. Dissertação de Mestrado - Departamento de Psicologia, Pontifícia Universidade Católica do Rio de Janeiro.

O presente trabalho se propõe a fazer um levantamento de estudos que concebam o autismo como um distúrbio de contato afetivo. Para isso, será utilizada a perspectiva desenvolvimentista que concebe que todo o desenvolvimento psicológico é fruto de uma construção social e não apenas uma maturação biológica determinista. O engajamento afetivo é o que possibilita o desenvolvimento da interação social da criança. Ocorrendo falhas na relação afetiva entre mãe e bebê podem ocorrer déficits no desenvolvimento das intersubjetividades primária e secundária. Como consequência, ocasionam prejuízos na comunicação e na fala. Por meio do estudo do desenvolvimento típico, veremos o que não ocorreu no autismo. Como uma forma de ilustrar a pesquisa serão apresentados relatos autobiográficos de pessoas portadoras do espectro autista. Esses fragmentos auxiliam na compreensão de como autistas vivenciam a questão afetiva.

\section{Palavras-chave}

Transtorno autista; engajamento afetivo; abordagem desenvolvimentista; desenvolvimento típico. 


\section{Abstract}

Ferreira, Beatriz Soares de Araujo; Lampreia, Carolina (Advisor). A study about affective connections in autism. Rio de Janeiro, 2014. 71p. MSc. Dissertation - Departamento de Psicologia, Pontifícia Universidade Católica do Rio de Janeiro.

This work proposes to make a raising of studies that conceive the autism as a disturbance of affective contact. To become it possible, the developmental perspective will be used because it conceives that every psychological development is the result of a social construction and not just a determinist biological maturation. The affective engagement is what makes possible the development of the child's social interaction. When failures occur in the affective relation between mother and baby, shortages can occur in the primary and secondary intersubjectivities. Damages in the communication and in the speech occur, as consequence. By the study of the typical development, we'll see what didn't occur in the autism. To illustrate the research, autobiographical narratives of people with autistic spectrum will be presented. These fragments help in the comprehension of how autistics live the affective matter.

\section{Keywords}

Autistic disorder; affective engagement; developmental approach; typical development. 


\section{Sumário}

1. Introdução 9

2. A conexão afetiva no desenvolvimento típico 15

2.1. A importância do desenvolvimento afetivo 16

2.2. Afeto 20

2.3. Intersubjetividade primária e comunicação afetiva 22

2.4. Intersubjetividade secundária e comunicação afetiva 24

$\begin{array}{ll}\text { 2.5. Teoria da Mente } & 27\end{array}$

3. As conexões afetivas no autismo 29

3.1. A importância do desenvolvimento afetivo no autismo 30

3.2. Afeto no autismo 31

3.3. Intersubjetividade primária no autismo 33

3.4. Intersubjetividade secundária no autismo 37

3.5. Teoria da Mente no autismo 41

4. Formas distintas de ser e estar no mundo: relatos autobiográficos 44

4.1. A memória e o resgate das lembranças 45

4.2. Memória individual, memória coletiva e memória histórica 46

4.3. Apresentação dos autores $\quad 48$

4.4. Fragmentos de relatos 49

4.5. Relatos e memória $\quad 59$

5. Conclusão 63

6. Referências bibliográficas $\quad 68$ 